\title{
Sedimentation process and vertical distribution of Cd in Jiaozhou Bay Dongfang Yang ${ }^{1,2,4, a}$, Danfeng Yang ${ }^{3}$, Sixi Zhu ${ }^{1,2}$, Zhikang Wang ${ }^{1,2}$ and Ming Wang $^{1,2}$ \\ ${ }^{1}$ Research Center for Karst Wetland Ecology, Guizhou Minzu University, Guizhou Guiyang, Guizhou Guiyang, China \\ ${ }^{2}$ College of Chemistry and Environmental Science, Guizhou Minzu University, Shanghai, 550025, China \\ ${ }^{3}$ College of Information Science and Engineering, Fudan University, Shanghai, 200433, China \\ ${ }^{4}$ North China Sea Environmental Monitoring Center, SOA, Qingdao 266033, China \\ adfyang_dfyang@126.com
}

Keywords: Cd, Distribution, Vertical distribution, Sedimentation process, Jiaozhou Bay.

\begin{abstract}
We analyzed the horizontal distribution, vertical distribution and sedimentation process of Cd in Jiaozhou Bay based on investigation data in April, July and October 1985. Results showed that Cd contents were in order of summer $>$ autumn $>$ spring. For spacial scale, the seasonal variations of $\mathrm{Cd}$ in surface and bottom waters were consist. For variation scale, the variation range of $\mathrm{Cd}$ in surface waters were bigger than in bottom waters due to the sedimentation and accumulation of $\mathrm{Cd}$, yet the difference was small. For vertical scale, Cd contents in surface and bottom waters were closed no matter Cd contents in waters were high or low. For regional scale, the Cd flux from inflow streams was the force of the vertical variations of Cd in surface and bottom waters. We defined the sedimentation process of $\mathrm{Cd}$ that for spatial-temporal variation, $\mathrm{Cd}$ in bottom waters was increasing continuously along with the sedimentation of Cd in and out of the bay. Furthermore, we defined the vertical distribution process of $\mathrm{Cd}$ in surface and bottom waters that the differences of $\mathrm{Cd}$ contents between surface and bottom waters were increasing along with time passed by, yet a new circle would begin in the following year.
\end{abstract}

\section{Introduction}

$\mathrm{Cd}$ is one of the most widely used heavy metal in industries (e.g., manufacture, electrolysis, metallurgical) and the excess emission of Cd-containing waste water and gas had been serious environment issues especially the Cd pollution in many marine bays [1-7]. Understanding the transformation and fate of $\mathrm{Cd}$ in marine bay is essential to marine environmental protection. Jiaozhou Bay is a semi-closed bay located in south of Shandong Peninsula, eastern Chin. This paper analyzed the horizontal distribution, vertical distribution and sedimentation process of Cd in Jiaozhou Bay based on investigation data in April, July and October 1985. Based on this research,we defined the sedimentation process of $\mathrm{Cd}$ that for spatial-temporal variation, Cd in bottom waters was increasing continuously along with the sedimentation of Cd in and out of the bay. Furthermore, we defined the vertical distribution process of $\mathrm{Cd}$ in surface and bottom waters that the differences of $\mathrm{Cd}$ contents between surface and bottom waters were increasing along with time passed by, yet a new circle would begin in the following year. These findings were helpful to provide scientific basis for the research on the source, pollution level and transfer process of Cd in sea waters.

\section{Material and method}

Jiaozhou Bay $\left(35^{\circ} 55^{\prime}-36^{\circ} 18^{\prime} \mathrm{N}, 120^{\circ} 04^{\prime}-120^{\circ} 23^{\prime} \mathrm{E}\right)$ is located in the south of Shandong Province, eastern China (Fig. 1). It is a semi-closed bay with the total area, average water depth and bay mouth width of $446 \mathrm{~km}^{2}, 7 \mathrm{~m}$ and $3 \mathrm{~km}$, respectively, and is connect to Yellow Sea in the south. 
There are more than ten inflow rivers (e.g., Haibo Rriver, Licun Rriver, Dagu Rriver, and Loushan Rriver), most of which have seasonal features $[8,9]$. The data was provided by North China Sea Environmental Monitoring Center. The survey was conducted in April, July and October 1985. Bottom water samples in three stations (i.e. 2031, 2032 and 2033) were collected and measured followed by National Specification for Marine Monitoring [10].

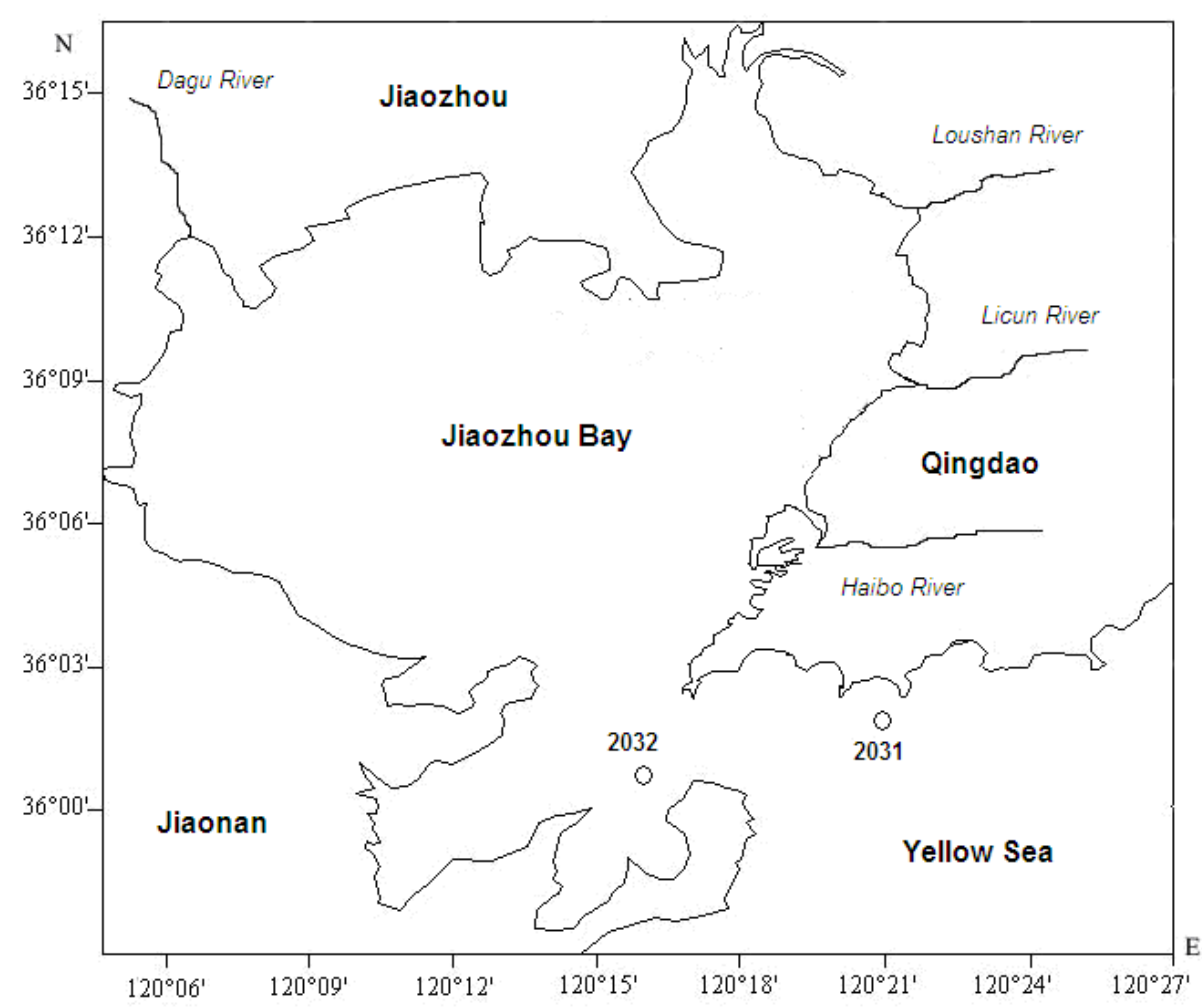

Fig. 1 Geographic location and sampling sites in Jiaozhou Bay

\section{Results}

Seasonal variations of $\mathbf{C d}$. Cd contents in surface waters in April, July and October in Jiaozhou Bay in 1985 were $0.19-0.44 \mu \mathrm{g} \mathrm{L}^{-1}, 0.16-0.21 \mu \mathrm{g} \mathrm{L}^{-1}$ and $0.03-0.39 \mu \mathrm{g} \mathrm{L}^{-1}$, respectively, while in bottom waters were $0.19-0.32 \mu \mathrm{g} \mathrm{L}^{-1}, 0.11-0.47 \mu \mathrm{g} \mathrm{L}^{-1}$ and $0.04-0.17 \mu \mathrm{g} \mathrm{L}{ }^{-1}$, respectively. April, July and October were spring, summer and autumn in study area. Cd contents in surface and bottom waters were both in order of spring $>$ autumn $>$ summer. The range of Cd contents in surface and bottom waters were 0.03-0.39 $\mu \mathrm{g} \mathrm{L}^{-1}$ and $0.04-0.32 \mu \mathrm{g} \mathrm{L}^{-1}$, and were very closed.

Horizontal variations of Cd. The three sampling Sites of 2031, 2032 and 2033 were located in the open sea, the bay mouth and the inside of the bay mouth, respectively. In April and October, Cd in both surface and bottom waters were both decreasing from the open sea to the bay mouth. In July, Cd contents in both surface and bottom waters were showing no obvious trends. In generally, the horizontal distributions of Cd contents in surface and bottom waters were same in different seasons.

Vertical variations of $\mathbf{C d}$. In April, Cd contents in surface waters were highest $(0.19-0.44 \mu \mathrm{g}$ $\left.\mathrm{L}^{-1}\right)$, yet in bottom waters were also highest $\left(0.19-0.22 \mu \mathrm{g} \mathrm{L}^{-1}\right)$. In July, Cd contents in surface waters were relative low $\left(0.16-0.21 \mu \mathrm{g} \mathrm{L}^{-1}\right)$, and in bottom waters were also relative low (0.11-0.17

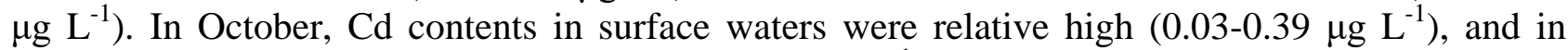
bottom waters were also relative low $\left(0.04-0.17 \mu \mathrm{g} \mathrm{L}^{-1}\right)$. It could be found that Cd contents in bottom waters would be relative high in case of $\mathrm{Cd}$ contents in surface waters were very high, while in case of Cd contents in surface waters were low or relative high, Cd contents in bottom waters would be relative low. In order to reveal the vertical variations of $\mathrm{Cd}$, the contents in surface waters in the sampling sites were subtracted from which in bottom waters, and the results were list in Table 1. In April, the differences ranged from 0.00 to $0.02 \mu \mathrm{g} \mathrm{L}{ }^{-1}$, and were positive in all of the three 
Sites. In July, the differences ranged from -0.01 to $0.04 \mu \mathrm{g} \mathrm{L}^{-1}$, and were positive in Site 2031 and 2033, yet were negative in Site 2032. In October, the differences ranged from -0.04 to $0.12 \mu \mathrm{g} \mathrm{L}^{-1}$. The subtractions in Site 2033 were positive, yet were negative in Site 2031 and 2032. For the whole year, the subtraction of $\mathrm{Cd}$ contents in surface from which in bottom waters ranged from -0.04 to $0.12 \mu \mathrm{g} \mathrm{L}{ }^{-1}$, indicated that Cd contents in surface and bottom waters were very closed.

Table 1 The subtracting Cd contents in surface waters from which in bottoms

\begin{tabular}{|c|c|c|c|}
\hline Month & 2031 & 2032 & 2033 \\
\hline April & Positive & Positive & Positive \\
\hline July & Positive & Negative & Positive \\
\hline October & Negative & Negative & Positive \\
\hline
\end{tabular}

\section{Discussion}

Seasonal variations process of $\mathbf{C d}$. In surface waters, Cd contents were decreasing from April $\left(0.44 \mu \mathrm{g} \mathrm{L}^{-1}\right)$ to July $\left(0.21 \mu \mathrm{g} \mathrm{L}^{-1}\right)$ due to a large amount of $\mathrm{Cd}$ in waters was absorbing and settling to the sea bottom under the force of gravity and current, yet were increasing from July to October $\left(0.39 \mu \mathrm{g} \mathrm{L}^{-1}\right)$ due to the accumulation of Cd in bottom waters along with time passed by. By means of vertical water's effect [10], Cd contents in bottom waters were mainly determined by which in surface waters and the accumulation of $\mathrm{Cd}$ in bottom waters, leading to the similar seasonal variations of Cd in surface and bottom waters.

Spatial sedimentation of Cd. In April, July and October, Cd was mainly sourced from stream flow and marine current, yet the source strength of stream flow were relative high, and the horizontal distributions of Cd were increasing from the bay mouth to the open sea. Due to a large amount of Cd was settling to the bottom waters rapidly by gravity and current, the horizontal distributions of $\mathrm{Cd}$ in bottom waters were increasing from the bay mouth to the open sea. For spatial scale, the horizontal distributions of Cd in surface and bottom waters were consist due a large amount of Cd was settling to the bottom waters rapidly by gravity and current. That was the spatial sedimentation process of $\mathrm{Cd}$.

Variation sedimentation of $\mathbf{C d}$. Cd contents in surface and bottom waters were very closed in April, July and October. Moreover, Cd contents in bottom waters would be relative high in case of Cd contents in surface waters were very high, while in case of Cd contents in surface waters were low or relative high, $\mathrm{Cd}$ contents in bottom waters would be relative low. These phenomenons were fully showing the vertical water's effect and horizontal waters's effect [11,12], and the accumulated effect and dilution effect working in case of low Cd content arrived bottom waters and high Cd content arrived bottom waters, respectively.

Vertical sedimentation of Cu. Cu contents in April, July and October were different, yet the loss ranges were $\left(0.03-0.04 \mu \mathrm{g} \mathrm{L}^{-1}\right)$ to $\left(0.44-0.32 \mu \mathrm{g} \mathrm{L}^{-1}\right)$, i.e., -0.01 to $0.12 \mu \mathrm{g} \mathrm{L}^{-1}$, indicating that there was little loss by means of vertical water's effect and horizontal waters's effect $[11,12]$. Hence, no matter Cd contents in were high or low, they were closed in both surface and bottom waters. In case of Cd contents were high or low, most of Cd were setting to bottom waters, so Cd contents in surface and bottom waters were consist.

Regional sedimentation of $\mathbf{C d}$. In regional scale, the subtractions of Cd contents in surface waters from which in bottom waters were also changing along with time. These differences were indicating the variations of Cd contents in surface and bottom waters. Once Cd was discharged to the bay from the sources, it was firstly reaching the surface waters, and than was settling to the bottom waters rapidly and continuously. In April, the source strength was highest, Cd contents in the waters were higher in surface waters than in bottom waters, indicating that the high Cd contents were transporting from the bay to the bay mouth and the open waters. In July, the source strength was relative low, Cd contents in the waters inside the bay and the bay mouth were higher in surface waters than in bottom waters, yet were reverse in the open sea, indicating that the relative low Cd contents were transporting from the bay to the bay mouth and the open waters, and the high 
sedimentation the the bay mouth. In October, the source strength was relative high, Cd contents in the waters were higher in surface waters than in bottom waters, Cd contents in the waters inside the bay and the bay mouth were higher in surface waters than in bottom waters, yet were reverse in the open sea, indicating that the relative high Cd contents were transporting from the bay to the bay mouth and the open waters, and the high sedimentation the the bay mouth and the open sea.

Sedimentation process of Cd. The major Cd source of Jiaozhou Bay was stream flow in April, July and October. In April, the wet season was coming and a large amount of Cd was discharged to the surface water of the bay via stream flow, and Cd contents in surface waters were showing decreasing trends along with the flow direction of the stream flow that from the inside of the bay to the bay mouth and to the open sea, as well as in bottom waters due to the sedimentation of Cd.

In July, a certain amount of Cd was discharged to the surface water of the bay via stream flow, and Cd contents in surface waters were showing decreasing trends along with the flow direction of the stream flow that from the inside of the bay to the bay mouth and to the open sea. However, be means of sedimentation and accumulation of $\mathrm{Cd}$ in the bay mouth, $\mathrm{Cd}$ contents in surface waters were higher than in bottom waters in the bay and the bay mouth, yet were reverse in the open sea.

In October, a certain amount of Cd was still discharged to the surface water of the bay via stream flow, and Cd contents in surface waters were showing decreasing trends along with the flow direction of the stream flow. However, be means of sedimentation and accumulation of $\mathrm{Cd}$ in the bay mouth, Cd contents in surface waters were higher than in bottom waters in the bay, yet were reverse in the open sea and the bay mouth.

The sedimentation process of Cd was that, high Cd-containing waste water was first discharged to the surface waters, in where there are a lot of suspended particulate matters whose surfaces were able to absorb a large amount of $\mathrm{Cd}$, and then $\mathrm{Cd}$ was transported to the bottom waters by means of gravity and current. Hence, at spatial scale, Cd contents were decreasing from the bay to the bay mouth and then to the open waters. At temporal scale, Cd contents were accumulating and increasing in bottom waters along with time. From April to July and October,the subtracting Cd contents in surface waters from which in bottoms were changing. In April, the differences were positive in all of the three Sites. In July, the differences were positive in two Sites. In October, the differences were positive only in one Site. These were revealing the sedimentation variations.

Meanwhile, the differences between $\mathrm{Cd}$ contents in surface and bottom waters were increasing along with time, i.e., from 0.00 to $0.02 \mu \mathrm{g} \mathrm{L}{ }^{-1}$ in April, to -0.01 to $0.04 \mu \mathrm{g} \mathrm{L}^{-1}$ in July, and to -0.04 to $0.12 \mu \mathrm{g} \mathrm{L}^{-1}$ in October. It could be found that the vertical distributions of Cd were homogeneous in April, and were being increasing along with time. Meanwhile, Cd contents in bottom waters were increasing along with the continuous sedimentation. Hence, the differences between Cd contents in surface and bottom waters were increasing along with time. However, in the coming year, if there was no Cd inputs, Cd contents in surface and bottom waters would be homogeneous again. That was the vertical distribution process between surface and bottom waters.

\section{Conclusion}

Cd contents in surface and bottom waters were both in order of spring $>$ autumn $>$ summer. By means of vertical water's effect, Cd contents in bottom waters were mainly determined by which in surface waters and the accumulation of $\mathrm{Cd}$ in bottom waters, leading to the similar seasonal variations of $\mathrm{Cd}$ in surface and bottom waters. For spatial scale, the horizontal distributions of Cd in surface and bottom waters were consist due a large amount of Cd was settling to the bottom waters rapidly by gravity and current. That was the spatial sedimentation process of Cd. For variation scale, Cd contents in surface and bottom waters were very closed in April, July and October by means of the vertical water's effect and horizontal waters's effect, and the accumulated effect and dilution effect working in case of low Cd content arrived bottom waters and high Cd content arrived bottom waters, respectively. For vertical scale, no matter Cd contents in were high or low, they were closed in both surface and bottom waters. In case of Cd contents were high or low, most of Cd were setting to bottom waters, so Cd contents in surface and bottom waters were consist. For regional scale, the subtractions of $\mathrm{Cd}$ contents in surface waters from which in bottom waters were also changing 
along with time. These differences were indicating the variations of $\mathrm{Cd}$ contents in surface and bottom waters.

We defined the sedimentation process of Cd that, high Cd-containing waste water was first discharged to the surface waters, in where there are a lot of suspended particulate matters whose surfaces were able to absorb a large amount of $\mathrm{Cd}$, and then $\mathrm{Cd}$ was transported to the bottom waters by means of gravity and current. We defined the vertical distribution process of Cd from surface and bottom waters that the vertical distributions of $\mathrm{Cu}$ were homogeneous in April, and were being increasing along with time. Meanwhile, Cd contents in bottom waters were increasing along with the continuous sedimentation. However, in the coming year, a new circle would begin.

\section{Acknowledgment}

This research was sponsored by Doctoral Degree Construction Library of Guizhou Nationalities University, Education Ministry's New Century Excellent Talents Supporting Plan (NCET-12-0659), the China National Natural Science Foundation (31560107), and Research Projects of Guizhou Nationalities University ([2014]02), Research Projects of Guizhou Province Ministry of Education (KY [2014] 266), Research Projects of Guizhou Province Ministry of Science and Technology (LH [2014] 7376).

\section{References}

[1] Yang DF and Miao ZQ: Marine Bay Ecology (I): Beijing, Ocean Precess, (2010):1-320. (in Chinese)

[2] Yang DF and Gao ZH: Marine Bay Ecology (II): Beijing, Ocean Precess, (2010):1-3320. (in Chinese)

[3] Yang DF, Chen Y, Wang H, et al.: Coastal Engineering, Vol. 29 (2010), p. 73-82.

[4] Yang DF, Chen Y, Liu CX, et al.: Coastal Engineering, Vol. 32 (2013), p. 68-78.

[5] Yang DF, Zhu SX, Wu YF, et al.: Applied Mechanics and Materials, Vols. 644-650 (2014):5325-5328.

[6] Yang DF, Wang FY, Wu YF, et al.: Applied Mechanics and Materials, Vols. 644-650 (2014): 5329-5312.

[7] Yang DF. Chen Y, Gao ZH, et al.: Proceedings of the 2015 international symposium on computers and informatics, (2015): 2667-2674.

[8] Yang DF, Chen Y, Gao ZH, et al.: Chinese Journal of Oceanology Limnoogy, Vol. 23(2005): 72-90.

[9] Yang DF, Wang F, Gao ZH, et al.: Maine Science, Vol. 28(2004): 71-74.

[10]State Ocean Administration. The specification for marine monitoring ( HY003.4-91): Beijing, Ocean Precess, (1991). (in Chinese)

[11] Yang DF, Wang FY, He HZ, et al.: Proceedings of the 2015 international symposium on computers and informatics, Vol. (2015): 2655-2660.

[12] Yang DF, Wang FY, Zhao XL, et al.: Sustainable Energy and Enviroment Protection, (2015): 191-195. 